
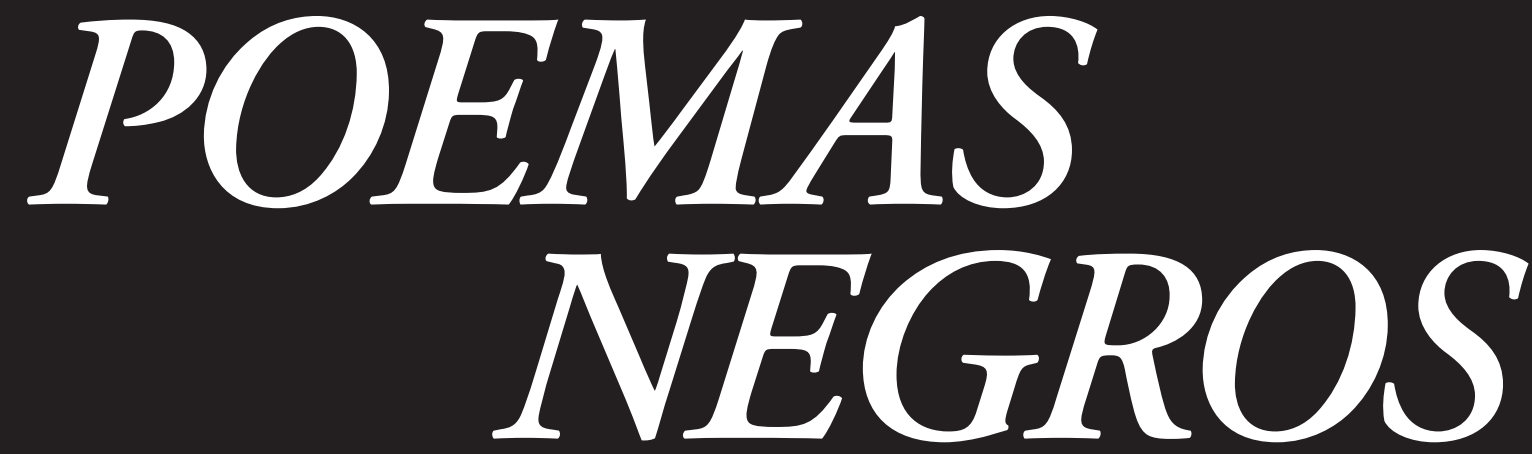

\title{
Um diálogo poético de Jorge de Lima e Gilberto Freyre
}

VAGNER CAMILO

\section{VAGNER CAMILO}

é professor de Literatura

Brasileira da USP e autor

de Drummond: da Rosa

do Povo à Rosa das Trevas

(Ateliê Editorial).

O presente ensaio reproduz, com pequenas modificacões, a comunicação apresentada na Jornada de Estudos Gilberto Freyre, organizada pelos professores Ethel $\mathrm{V}$. Kosminsky Fernanda Arêas Peixoto e Claude lèpine na Universidade Estadual Paulista (Unesp), em novembro de 2000, por ocasião das comemoracõoes do centenário de nascimento do antropólogo pernambucano. 


\section{"Era a negra Fulô que nos chamava}

de seu negro vergel $[\ldots]$

canções de lavadeira ao pé da fonte,

era a fonte em si mesma, eram nostálgicas

emanações de infância e de futuro,

era um ai português desfeito em cana"

(Carlos Drummond de Andrade,

“Conhecimento de Jorge de Lima”).

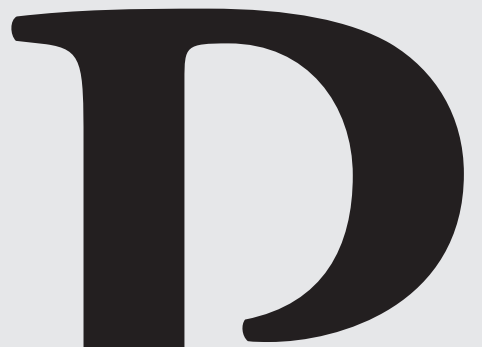

ublicado em 1947, Poemas Negros reunia textos de 1927

(1) até cerca de 1940. "Pode-se pensar", com Alexandre

Eulálio, "que a edição promovida pela Revista Acadêmica

de Murilo Miranda tenha sido inspirada pelo apareci-

mento em 46, em Buenos Aires, do Mapa de la Poesía

Negra Americana, compilado, prefaciado e anotado pelo

poeta cubano Emilio Ballagas, autor do Cuaderno de

Poesía Negra(1931)e, ao lado de Nicolás Guillén e Manuel

del Cabral, um dos estabilizadores da poesia afro-antilha-

na. ('Essa Negra Fulô’ em edição bilíngüe é a única peça

brasileira da coletânea)" (2).

Já recolhidos em coletâneas anteriores: Poemas (1927), Novos Poemas (1929) e Poemas Escolhidos (1932). Todas as menções feitas aos poemas de Jorge de Lima referem-se à seguinte edição: Poesias Completas, Rio de Janeiro/Braślia, losé Aguilar/INL, 1974.

Alexandre Eulálio, "A Obra e os Andaimes: os Trinta Anos da Morte de Jorge de Lima", in Escritos, Campinas/São Paulo, Ed. da Unicamp/Ed. da Unesp, 1992, p. 481. 


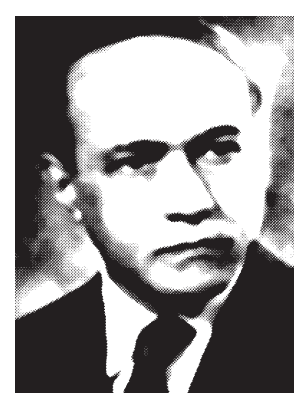

Não bastasse o privilégio das ilustrações de Segall, a edição numerada de Poemas Negros trazia ainda um prefácio daquele cujo pensamento, afinal de contas, havia atuado, em boa medida, na gênese desses mesmos versos: Gilberto Freyre. O prefácio interessa por mais de um motivo, além, é claro, do que revela sobre a poesia negra de Jorge de Lima - da qual me ocuparei adiante.

Primeiramente, ele surpreende por nada ostentar da antiga animosidade para com o modernismo paulista, ao qual se refere expressamente. Rompe-se, assim, com a imagem do líder empenhado em reivindicar a todo custo não só a maior importância, como também a plena autonomia do movimento regionalista do Nordeste, sobretudo em relação a possíveis influências provenientes do modernismo paulista visto como produto da emulação européia e, portanto, longe das nossas raízes autênticas. Tamanho empenho já foi interpretado como decorrência do ressentimento pela perda do poder econômico e político da região nordestina em benefício, justamente, do Centro-Sul (em especial, São Paulo). Buscava-se, assim, agonicamente, uma compensação, no plano da cultura, a essa perda, reivindicando para o Nordeste o papel de depositário das raízes mais autenticamente brasileiras, porque não sujeito, como o Centro-Sul, às influências vindas de fora (3).

Sem deixar de insistir na importância e distinção de "um movimento nordestino de renovação das letras, artes e cultura brasileira", o fato é que o prefácio de Freyre fala agora em termos de troca, de reciprocidade. Uma via de mão dupla entre o modernismo paulista e o "movimento do Nordeste", definido (numa humildade em boa medida retórica, é verdade) como uma espécie de "parente pobre", capaz entretanto, no dizer de Freyre,

Ver, em especial, José Mauricio Gomes de Almeida, A Tradição Regionalista no Romance Brasileiro, Rio de Janeiro, Topbooks, 1999; e Moema Selma D'Andreia, A Tradição Re/des/coberta: Gillberto Freyre e a Literatura Regionalista, Cam pinas, Ed. Unicamp, 1992 viva constituída por elementos genuinamente brasileiros, essenciais ao desenvolvimento da nossa cultura em expressão honesta do nosso ethos, da nossa história e da nossa paisagem e em instrumento de nossas aspirações e tendências sociais como povo tanto quanto possível autônomo e criador".

Essa influência é reconhecida, inclusive e sobretudo, em uma das expressões mais autênticas desse movimento nordestino: a poesia afro-nordestina do autor de "O Mundo do Menino Impossível”.

Afora a atitude em face do modernismo, o prefácio também surpreende pelo modo como Freyre rompe certo consenso em torno do confronto entre a poesia negra do Brasil e a dos Estados Unidos: enquanto esta, feita pelos próprios negros, parece, para alguns, guardar certa vantagem (se é possível colocar a questão nesses termos) em relação à primeira, feita predominantemente por brancos, numa atitude que bem atesta sua dimensão paternalista, para Freyre, ao contrário, a vantagem estaria conosco. A seu ver, a poesia negra norteamericana, justamente porque feita por negros, revelaria um caráter segregacionista e ressentido, hostil em relação ao branco, ao passo que a brasileira seria produto do fraternalismo e da democracia, de que é exemplo a obra de, entre outros, um Castro Alves, um Ascenso Ferreira, o próprio Mário de Andrade e, é claro, Jorge de Lima.

Passemos enfim a este último - ou melhor, às considerações de Freyre a propósito da poesia afro-brasileira do poeta alagoano em que se reconhece muito da influência de seu próprio pensamento. Leitor e mentor intelectual encontram-se, assim, na nostalgia do bangüê e das relações cordiais por ele engendradas, em oposição à usina; no mito da “democracia racial"; ou mesmo no "estilo franciscano" da lírica limiana. Além disso, é possível reconhecer em muitos poemas um movimento solidário em direção ao negro - ressaltado, aliás, pelo próprio prefaciador - que, sem refutar de todo, tende todavia a relativizar o famigerado compromisso de classe da ótica 
de Freyre (ótica da casa-grande, diriam alguns) e dos que se orientaram por ela. Vejamos alguns desses aspectos ressaltados pelo prefaciador, a começar pela tão polêmica democracia racial.

Se, de acordo com Hermano Vianna, o mito da "democracia racial" imputado a Freyre é expressão completamente ausente em Casa-Grande \& Senzala, sendo uma atribuição mal-intencionada da crítica, resultante de uma "leitura apressada, tendenciosa ou burra" (4), o fato é que, ao menos no referido prefácio, ela figura com todas as letras.

Mas veja que, ao admitir a presença dessa referência explícita, não preciso necessariamente engrossar o coro daqueles leitores burros ou tendenciosos, contra os quais investe tão acerbamente o mesmo Vianna, pois sou o primeiro a reconhecer que o aparente comprometimento ideológico associado à expressão tende a ser relativizado quando Freyre especifica a natureza dessa democracia, que nada tem de ingenuamente igualitária, pois o prefácio fala, de forma diferençada, em "contato democratizante para os brancos e degradante para os negros".

É bem verdade que nos versos do justamente intitulado "Democracia", Jorge não chega a sinalizar esse duplo movimento, na medida em que ressalta apenas o que resultou da mistura para o branco (no caso, para o próprio sujeito lírico), ou seja, a dissolução do eu para melhor amar "em todas as línguas de branco, de mouro ou de pagão". Apesar disso, pode-se dar crédito a esse empenho amoroso e solidário, pois outros poemas do livro tratarão de confirmálo ao flagrar a realidade do negro por uma ótica que se poderia dizer mais próxima à da senzala. Isso, é claro, sem se confundir com ela-o que, mais do que ingênuo, seria ideologicamente comprometedor -, pois Jorge tem consciência da realidade e da distância social de sua condição. Como bem nota o prefaciador, "a metade aristocrática desse nordestino total, de corpo colorido por jenipapo e marcado por catapora, não [esquece] que 'a bisavó dançou uma valsa com D. Pedro II', nem que o avô teve bangüêe”.
Por vezes, é fato, essa metade aristocrática parece avultar e comprometer a ótica por que é flagrada a realidade do negro, tal como ocorre no poema justamente intitulado "Bangüêe", correspondente em verso à prosa homônima de Lins do Rego. Em meio a um verdadeiro ubi sunt, a evocação nostálgica dos bangüezinhos da infância - feita, inclusive, pela ótica infantil, visível no uso recorrente dos diminutivos - , temos uma visão paternalista, condescendente e festiva do negro entregue a momentos de ócio e à bebida em meio à lida, que encontra respaldo em Freyre e Lins do Rego ao caracterizar as relações cordiais de senhores e cabras nos engenhos por oposição às usinas.

Todavia, por mais nostálgico e comprometido que seja, esse retrato do trabalho negro no engenho também não deixa de ser um modo de resistência à ética protestante do trabalho, na esteira da preguiça ingênita celebrada pelo Macunaíma de Mário de Andrade e pelos demais modernistas do sul - conforme sinalizou Roberto Schwarz, ao tratar da "visão desideologizada do esforço" em Machado de Assis e no grupo de 22 (5). Ora, essa ética protestante comparece nos versos de "Bangüê" associada à Usina Leão, "triste como uma igreja sem sino", como "um templo evangélico". Assim como, nela, o cozinhador Mister Cox "tira da cana o que a cana não pode dar/ e [...] não deixa nem bagaço/com um tiquinho de caldo/para as abelhas chupar"; também ela extrai o prazer a "alegria das bagaceiras", traduzidas nas "cantigas da boca da moenda" entoadas pelos cabras do eito, nas sestas em meio à lida dos "bebedores de resto de alambique", nas missas e feiras domingueiras em torno à capela do velho bangüê. Isso, certamente, pela disciplina austera da ética protestante associada ao trabalho (6).

Nessa oposição marcante ao protestantismo e à ética que ele impõe não só ao trabalho, mas a toda a existência regida pela observância daquele princípio de constância que, segundo Edmund Leites, resume a totalidade da visão de mundo protestante, é ainda possível reconhecer a presença sorrateira de Freyre. Penso aqui não só na for-

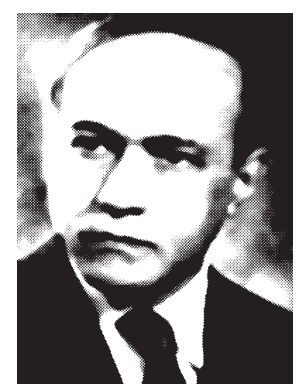

Hermano Vianna, "Equilíbrio de Antagonismos", Suplemento Mais! da Folha de S. Paulo São Paulo, 12/mar./2000 p. 21

5 Roberto Schwarz, Um Mestre na Periferia do Capitalismo Machado de Assis, São Pauo, Duas Cidades, 1990

A referência à ética protestante, aqui, é, sem dúvida, o clás sico estudo de Max Weber, A Etica Protestante e o Espírito do Capitalismo, São Paulo, Pio neira Thomson learning, 2001 
7 Paul Freston apud Ricardo Benzaquen de Araújo, Guerro e Paz: Casa-Grande \& Senza la e a Obra de Gilberto Freyre nos Anos 30, Rio de Janeiro Ed. 34,1994 , p. 100

8 Idem, ibidem, p. 101

9 Alfredo Bosi, História Concisa da Literatura Brasileira, São Paulo, Cultrix, 1975.

$10 \mathrm{E}$ o franciscanismo é outro traco afim à ótica de Gilberto Freyre, que inclusive reconhe ceu nele, no fraternalismo franciscano, uma forma de resistência ao autoritarismo $\mathrm{po}$ triarcal lcf. Ricardo Benzaquen de Araúio op cit. |. Ele compoece, entre outros momentos d sua obra, no ensaio sobre Whitman, uma das referências para a poesia de Jorge - que chega a evocá-lo como interlocutor ideal de "Democracia". Esse interesse partilhado pelo grupo em torno de Gilberto Freyre far-se-ia ainda senti de forma literariamente mais produtiva, no estilo humilde / sermo humilis) da lírica bande riana, como demonstra a conhecida análise de Davi Arrigucci r., Humildade, Parxão e Morte: a Poesia de Ma nuel Bandeira (São Paulo, Companhia das Letras, 1990). No caso de Jorge, o franco interesse por S. Francisco comparecerá em mais de um poema em uma biografia para crianças IVida de S. Francisco de Assis).

11 Ouso e o sentido das enumera cões na poesia de Jorge de Lima foram examinados em perspec tivas diversas por Ledo lvol "Rol de Insulindias" in Poesia Observada, São Paulo, Duas Cldades, 1978) e Roger Bastide ("Doçura do Leite das Negras", in Letras e Artes, São Paulo, 22 fev./1948). Devo a cópia do artigo de Bastide a Fernanda Peixoto.

12 Cf. introdução à obra comple ta de Jorge de Lima.

13 Mas se a intenção era apaga tais traços, por que fazer fig rar as duas versões na obra completa, quando poderia ter substituído uma pela outra? Essa indagação é feita por Rodolfo llari, que busca outras razões além dessa para a segunda versão do poema lver "Os Poe mas Negros de Jl", in Nossa América, São Paulo, nov-dez. 1991 pp. 8-131. Seja como for, o fato é que esses traços de sujeira e animalidade aparecem ainda de forma mais ou menos ambígua, em dois ou três outros poemas, representando, sem dúvida, a dimensão comprometedora das figurações mais antigas do negro em Jor ge de Lima. mação protestante do antropólogo de Apipucos, com a qual viria se desencantar depois, acabando, segundo Freston, por conceber "uma teoria do Brasil baseada precisamente no que poderá ter sido o centro de seu conflito com o protestantismo. Pois nada mais distante da moral sexual protestante do que a prática sexual do português desgarrado nos trópicos" (7). Penso ainda, e principalmente, na interpretação de Ricardo Benzaquen de Araújo, para quem o protestantismo é uma presença em negativo que atravessa toda a opus magnum de Freyre. Basta apenas, diz ele, "que nos lembremos, por exemplo, da vigorosa afirmação da magia, do ócio e de todos os tipos de excesso, particularmente os sexuais, para que se confirme que estamos realmente diante de uma civilização povoada pelo pecado, o exato oposto, por conseguinte, daquele ideal de perfeição terrena, fundado no elogio do trabalho sistemático, da ética, do isolamento e do autocontrole que a doutrina puritana costuma pregar" (8). Todas essas considerações vão encontrar ressonância no poema de Jorge de Lima.

Mas, à exceção dessa ótica comprometedora por que é figurado o negro em "Bangüê", há mais de um poema do livro de 47 em que a distância de classe do neto do senhor de engenho não impede aquele movimento solidário a que me referia anteriormente. Essa ótica fraterna já havia sido assinalada de passagem por Alfredo Bosi a propósito do poema que dá fecho à coletânea ("Olá! Negro”), observando, inclusive, que ela irmana a poesia negra à bíblicocristã de Jorge de Lima na "assunção das dores do oprimido, socialismo inerente a toda interpretação radical dos Evangelhos" (9). E será justamente evidenciando essa "cordialidade crioula", cristã ou, mais especificamente, "franciscana" (10), que Gilberto Freyre buscará rebater a acusação de gulodice de pitoresco, freqüentemente endereçada aos poemas afro-nordestinos de Jorge, justamente por aqueles que, segundo o prefaciador, são os "menos autorizados para fazê-la, tal a sua pobreza de experiência genuinamente brasileira; pois são cosmopolitas pouco sensíveis aos caracte- rísticos mais profundos da vida, do passado e da paisagem das nossas várias regiões; geômetras que desconhecem as intimidades de nossa paisagem humana".

Por mais relevantes que me pareçam os argumentos de Freyre, não posso deixar de considerar que certa concessão ao pitoresco foi reconhecida até mesmo por admiradores confessos de Jorge de Lima, como Alexandre Eulálio. Talvez tendo em mente a perspectiva por vezes exterior, distanciada e brejeira do negro. Ou quem sabe o gosto pelos grandes mosaicos obtidos à custa da enumeração (11), pois já houve quem falasse que ela se esgota com freqüência no gosto pela enfiada de nomes bantos e bundos de comidas, lugares, mitos e feitiços. Seja como for, a dita concessão ao pitoresco, nem sempre devidamente precisada pelos críticos, não chega a comprometer o conjunto da coletânea, e a meu ver se faz sentir nos poemas mais antigos - nos quais a visão distanciada, objetiva e por vezes brejeira do negro pelo branco que fala de outro lugar social não chega, entretanto, a abolir a notação sociologicamente precisa.

Já nos poemas posteriores que constituem, de fato, a parte nova da antologia de 47 , é que vemos como a ação do tempo - a par daquela interiorização progressiva que, segundo Waltensir Dutra (12), marca a trajetória poética de Jorge de Lima - favoreceu a adoção de uma perspectiva mais aprofundada e de uma atitude solidária, insistentemente referida aqui. Para melhor apreendê-las, vale a pena confrontar alguns poemas mais antigos com outros mais recentes que tratam exatamente dos mesmos temas, como se Jorge buscasse retomá-los para melhor aprofundá-los.

Esse aprofundamento poderia, em dada medida, ser também considerado na reescritura de um poema como "Xangô", cuja versão final, constante do livro de 47 , foi vista por alguns como uma "tentativa de apagar alguns traços de sujeira e animalidade" (13), demasiadamente fortes, na descrição da macumba, presentes na primeira versão de Poemas (1927). Mais interessante, entretanto, me parece flagrar o 
aprofundamento de visão e o gesto solidário em poemas como "História" quando confrontado com a antológica "Negra Fulô" do livro anterior, que dá a impressão de saltar diretamente das páginas de Casa-Grande \& Senzala. Apesar das imagens afins, especialmente no que toca à sedução do sinhô pela negra e à vingança da sinhá enciumada, a perspectiva brejeira com que Lima enfocava Fulôé aqui abandonada em favor da ótica solidária, irmanada ao sofrimento da ex-princesa africana, adquirida por um “caco de espelho”, deflorada pelo capitão, possuída pelos marinheiros e ferrada com uma âncora nas ancas, durante a travessia para o Brasil, onde elevou em vão a voz em nagô para Oxalá, surdo a seus apelos.

$\mathrm{O}$ que me parece significativo em poemas como "História" é o modo como o enfoque lírico de Jorge, sem dispensar a notação direta e objetiva, tende a privilegiar os mecanismos compensatórios, acionados imaginariamente pelo negro na tentativa de evadir-se (14) vicariamente (ao menos) do horror de sua condição, à qual não faltam, bem o sabemos, requintes de perversidade de que Casa-Grande \& Senzala é pródigo em exemplos, a despeito da "visão edulcorada da colonização" em que insistem muitos de seus leitores. Tais mecanismos traduzem-se ora na religião, na magia e nas mandingas, como no próprio "História", em "Xangô", "Quando Ele Vem", entre outros; ora no fumo (maconha), como no mesmo "Xangô" e "Cachimbo do Sertão". Podem, ainda, assumir formas mais elaboradas, inclusive artisticamente, de que é exemplo a música, em sua riqueza e variedade de ritmos, como se vê em poemas como "Pra Donde Você me Leva" e "Olá! Negro".

Mas há ainda formas extremadas de evasão e alienação, como a loucura de "Maria Diamba", falando só diante da ventania que vem do Sudão:

"Para não apanhar mais

falou que sabia fazer bolos:

virou cozinha.

Foi outras coisas para que tinha jeito.

Não falou mais:
Viram que sabia fazer tudo, até molecas para a Casa-Grande.

Depois falou só,

só diante da ventania que ainda vem do Sudão; falou que queria fugir dos senhores e das judiarias deste mundo para o sumidouro".

Precursor de "Maria Diamba", “Joaquina Maluca” já tateava também, nos anos 20 , as causas e o significado da leseira da negra, embora de maneira ainda um tanto dubitativa e comprometida pela já mencionada visão moral de sujeira e vício. Não deixava, entretanto, de eximi-la de qualquer culpa:

“Joaquina Maluca, você ficou lesa não sei por que foi! Você tem um resto de graça menina, na boca, nos peitos, não sei onde é...

Joaquina Maluca, você ficou lesa, não é?

Talvez pra não ver

o que o mundo lhe faz.

Você ficou lesa, não foi?

Talvez pra não ver o que o mundo lhe fez. Joaquina Maluca, você foi bonita, não foi? Você tem um resto de graça menina não sei onde é...

Tão suja de vício, nem sabe o que o foi.

Tão lesa, tão pura, tão limpa de culpa, nem sabe o que é!'”

Mas, quando nem mesmo a loucura é suficiente para aliviar os padecimentos da realidade aviltante, resta a decisão trágica que corresponde à derradeira forma de evasão: a morte, representada pelo afogamento de Celidônia, a "linda moleca ioruba" de "Ancila negra", que foi babá de Jorge na infância e com quem - como de praxe parece ter despertado para o sexo, conforme sugerem alguns dos versos. A curiosa ênfase na necessidade de "recalque", reiterada no poema e associada à lembrança da
14 Esse caráter evasivo já foi, em parte, sinalizado por Rodolfo llari no ensaio citado. 
morte de Celidônia, talvez se justifique pelo fato de ela ter-se tornado verdadeira "obsessão durante toda a vida [do poeta], em particular no final, nas insônias trazidas pela doença", segundo depoimento do amigo e confidente José Fernando Carneiro (15).

A meu ver, entretanto, isso não explica tudo. Tamanha ênfase parece atender à necessidade de aplacar a consciência dolorosa de uma culpa evidentemente social, de classe, própria do neto de senhor de engenho, que se sente responsável pela morte da moleca, para quem essa era a única forma de fuga e libertação de sua condição - e é bem o número considerável de suicídios entre os negros mergulhados no banzo. Nesse sentido, as duas últimas estrofes do poema são mais significativas:

"Há muita coisa a recalcar e esquecer: o dia em que te afogaste, sem me avisar que ias morrer, negra fugida na morte, contadeira de histórias do teu reino, anjo negro degredado para sempre, Celidônia, Celidônia, Celidônia!

Depois: nunca mais os signos do regresso. Para sempre: tudo ficou como um signo [ressoando.

E eu parado em pequeno, mandingando e dormindo, muito dormindo mesmo".

Diante de poemas como esse, torna-se, mesmo, difícil afirmar uma perspectiva exterior e puramente pitoresca, como queriam alguns dos críticos de Jorge de Lima, obrigando-nos a dar razão a Gilberto Freyre. Mesmo que eles não correspondam à totalidade, nem sequer à maior parte da coletânea, com certeza obrigam os intérpretes mais conseqüentes a certa cautela na acusação em bloco de gulodice de pitoresco.

Um derradeiro confronto poderia ser estabelecido entre o mais antigo "Cantigas" e o posterior "Zefa Lavadeira", um dos três poemas em prosa do livro, que é, na verdade, um trecho de $\mathrm{A}$ Mulher Obscura (1939), num exemplo do constante rea- obra que se estende até o último livro (Invenção de Orfeu). Tanto um quanto outro versam sobre um tema caro à lírica de Jorge de Lima, embora recorrente na nossa tradição: a imagem das lavadeiras durante ou depois da lida.

$\mathrm{Na}$ verdade, o primeiro retrata mais as cantigas melancólicas entoadas pelas lavadeiras pensativas durante a lavagem e que, pela sua beleza e leveza, têm o poder de lavar "as almas dos pecadores". Ou melhor, de lavar "as almas negras" que "pesam tanto" e "são tão sujas como a roupa". Já no poema em prosa, vemos o poeta espreitando o banho da lavadeira, após a faina (como o faria em outro poema em prosa do livro, na companhia de um amigo de infância). O quadro belíssimoé traçado com a delicadeza da mão de um mestre-maestria de poeta-pintor -, num crescendo de erotismo que acompanha as rotas da mão de Zefa pelo corpo moreno até chegar ao sexo, no qual, diz o fecho do poema, "a África parece dormir o sono temeroso de Cam":

"[...] Depois de lavar a roupa dos outros, Zefa lava a roupa que a cobre no momento. Depois, deixa-a corando sobre o capim. Então Zefa lavadeira ensaboa o seu própria corpo, vestido do manto de pele negra com que nasceu. Outras Zefas, outras negras vêm lavar-se no rio. Eu estou ouvindo tudo, eu estou enxergando tudo. Eu estou relembrando a minha infância. A água, levada nas cuias, começa o ensaboamento; desce em regatos de espuma pelo dorso, e somese entre as nádegas rijas. As negras aparam a espuma grossa, com as mãos em concha, esmagam-na contra os seios pontudos, transportam-na, com agilidade de símios, para os sovacos, para os flancos; quando a pasta branca de sabão se despenha pelas coxas, as mãos côncavas esperam a fugia espuma nas pernas, para conduzi-la aos sexos em que a África parece dormir o sono temeroso de Cam".

O confronto entre ambos os poemas, por um lado, revela um ganho para “Zefa Lavadeira" no sentido do aprofundamento de visão e de abandono daquela imagem 


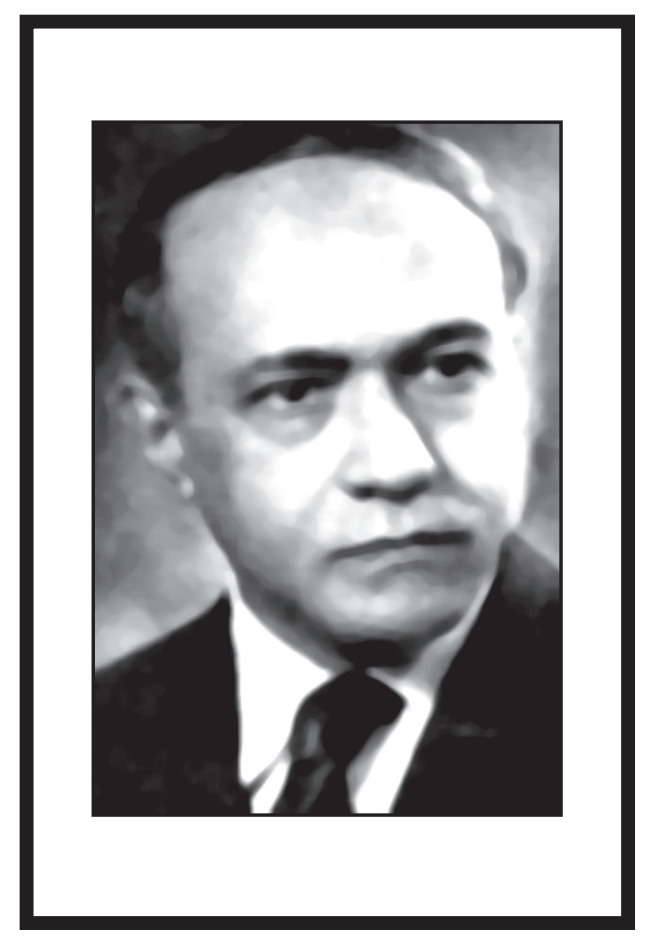

comprometedora de sujeira, que ainda desponta de forma ambígua em "Cantigas". Por outro lado, entretanto, desponta um comprometimento de natureza diversa, que não se limita à comparação com os símios, mas diz respeito ainda à explicação mítica da escravidão, evocada ao final do poema. Nessa evocação do mito bíblico de Cam (16), Jorge foi antecedido por Castro Alves - a quem, vale lembrar, o poeta alagoano dedicaria uma espécie de biografia em versos, bem ao sabor do cancioneiro popular. A menção ao mito em "Vozes d'África" foi objeto de uma análise arguta de Alfredo Bosi, que nela reconheceu um "arcaísmo de perspectiva" e uma contradição de base no projeto libertário do nosso poeta dos escravos, na medida em que, ao explicar o fenômeno total do cativeiro como produto de uma culpa exemplarmente punida, acaba por justificá-la. Como lembra o crítico, a "referência à sina de Cam circulou entre os séculos XVI e XVIII, quando a teologia católica ou protestante se viu confrontada com a generalização do trabalho forçado nas economias coloniais. $\mathrm{O}$ velho mito serviu então ao novo pensamento mercantil, que o alegava para justificar o tráfico negreiro, e ao discurso salvacionista, que via na escravidão um meio de catequizar populações antes entregues ao fetichismo ou ao domínio do Islão. Mercadores e ideólogos religiosos do sistema conceberam o pecado de Cam e a sua punição como o evento fundador de um sistema imutável". Por mais paradoxal que pareça, foi justamente com o mito da danação de Cam e seus descendentes que o vate libertário de 1868 deu forma poética às suas "Vozes d'África". Vozes de uma África que, através da prosopopéia, alcança o estatuto de um ser individual, ao qual se une a voz do poeta para, juntos, sofrerem e suplicarem, impotentes, a um deus absconditus num céu deserto. "Aqui triunfa o absurdo de um castigo por uma culpa remota: daí a tragicidade da situação de um continente inteiro à mercê [da] cólera onipotente" de um “Deus terrível”, inamovível diante dos apelos de uma raça que, sem mesmo saber o motivo de sua pena, vê-se irremediavelmente sujeita ao efeito do anátema que "se reproduz de geração em geração, de tal modo que a sequiência dos tempos [...] em nada altera a intensidade da maldição original." Assim, ao inscrever o destino dos africanos na esfera do mito, o nosso poeta da abolição acabava, por mais contraditório que pareça, por reiterar e justificar o irremediável da condição escrava (17).

Muito embora não haja, em Jorge, a contradição de base da poesia castralvina, entre o anseio libertário e a naturalização mítica da escravidão, esta entretanto tende a ser perpetuada: uma vez fecundado, o ventre de Zefa fará despertar a antiga maldição que paira sobre sua raça, justificando o horror da condição a que se encontra relegada. Nesse sentido, a formação e a perspectiva cristãs de Jorge se, por um lado, possibilitaram a atitude fraterna, franciscana em relação à dor do negro, tão louvada por Freyre, por outro ameaçaram-no de descambar para aceitação conformista dessa mesma dor expiatória - nisso se afastando por completo da lição do mestre de Apipucos que, de acordo com um de seus melhores intérpretes, furtouse por completo à explicação mítico-cristã da escravidão (18).

\section{O poeta Jorge \\ de Lima}

